\title{
The Effect of Systemic Methotrexate and Cyclosporine Combination Therapy inPsoriasis Vulgaris Patients in Bandung, Indonesia
}

\author{
Oki Suwarsa ${ }^{D}$, Fatima Aulia Khairani, Syawalika Ulya Isneny, Erda Avriyanti, \\ Hartati Purbo Dharmadji, Miranti Pangastuti, Endang Sutedja, Hendra Gunawan \\ Department of Dermatology and Venereology, Faculty of Medicine, Universitas Padjadjaran - Dr. \\ Hasan Sadikin Hospital, Bandung, Indonesia
}

\begin{abstract}
Background: Methotrexate (MTX) and cyclosporine have been used as effective systemic mono-therapy for psoriasis. Several factors are considered to switch monotherapy to combination therapy because monotherapy is no longer effective and has higher side effects. Hence,clinicians have avoided systemic therapy combinations due to its toxicity. However, some studies showed that this combination therapy could be usedeffectively for psoriasis patients. Purpose: This study aimed to analyze the efficacy and adverse effects of systemic MTX and cyclosporine combination therapy in Indonesian psoriasis vulgaris patients. Methods: The retrospective study assessed the effectiveness of 3 monthsmono-therapyand combination therapy of systemic MTX and cyclosporine in psoriasisvulgaris patients from 2016-2017 in Dermatology Clinic, Dr. Hasan Sadikin Hospital, Bandung, West Java, Indonesia. Result: Psoriasis area and severity index (PASI) score 90 were achieved in the group MTX (50\%) and cyclosporine group (50\%), while none in the combination group.However, eight patients $(50 \%)$ in group MTX and cyclosporine reached the primary endpoint of PASI 50. One patient in cyclosporine group had adverse effects on kidney profiles. Nonetheless, other patients had no biochemical changes. But, there was no significant difference in the change of PASI between each group $(\mathrm{p}=0.102)$. Conclusion: We propose that combination therapy of MTX and cyclosporine is relatively safe and efficacious in treating Indonesian psoriasis vulgaris patients. This combination treatment isas effective as MTX or cyclosporinemono-therapy.
\end{abstract}

Keywords: cyclosporine, methotrexate, psoriasis vulgaris.

Correspondence: Erda Avriyanti, Department of Dermatology and Venereology, Faculty of Medicine, Universitas Padjadjaran - Dr. Hasan Sadikin Hospital, Bandung, Jawa Barat, 40161, Indonesia, Phone: +62222032426 ext. 3449, E-mail: erda.avriyanti@unpad.ac.id.

Article info | Submited: 3-5-2021, Accepted: 22-5-2021, Published: 30-11-2021

\section{BACKGROUND}

Psoriasisis an immunologically mediated, inflammatory disease characterized by skin inflammations and epidermal hyperplasia. ${ }^{1}$ Since the treatment of psoriasis is not curative and aimed at prompting control of clinical manifestations, the optimal choice of psoriasistherapies is to improve the quality of life and the level of acceptance of the disease for patients. ${ }^{2}$

Methotrexate (MTX) and cyclosporine are effective mono-therapy for moderate and severe psoriasis. ${ }^{3}$ MTX is a derivative of aminopterin that produces anti-proliferative, anti-inflammatory, and immunosuppressive effects, ${ }^{4}$ used when topical treatments and phototherapy are ineffective or impractical. ${ }^{5}$ Oral MTX is effective for treating psoriasis, though subcutaneous administration yields a more favorable pharmacokinetic profile. $^{4}$ Cyclosporine induces immunosuppression that suppresses $\mathrm{T}$ lymphocyte function via inhibition of intracellular calcineurin, resulting in decreased interleukin (IL)-2 and interferon- $\gamma$ production. ${ }^{6,7}$ Cyclosporine is often used as first-line therapy in moderate to severe forms of psoriasis by several dermatologists. ${ }^{2}$

The management of psoriasis is complex and usually needs a patient-tailored approach. Combination therapies of MTX and cyclosporine could increase the clinical response and enhance patients' safety profiles. ${ }^{2}$ Several factors were considered to switch monotherapy to the combination. Conventional combination therapy combines two or more agents with synergistic or complementary action, allowing lower-dose, toxicity-sparing regimens of each of the agents. ${ }^{7}$ However, combination therapy of MTX and cyclosporine has been discouraged by therapeutic guidelines due to MTX toxicity. It is also concerned that both drugs will mutually increase the blood levels and decrease the elimination from the body. ${ }^{3}$ While, a recent study showed the safe use of these combinations for psoriasis patients, with reversible side effects by reducing dose and cessation of therapy. ${ }^{3}$ 
Combination therapy of MTX and cyclosporine may become a reasonable option for psoriasis due to the lack of irreversible adverse effects. ${ }^{3}$ Therefore, we undertook a record review to look at our experience using MTX, cyclosporine, and those combinations for psoriasis vulgaris patients in Bandung, West Java, Indonesia.

\section{METHODS}

We conducted a retrospective study from the patients treated with MTX and cyclosporine as monotherapy, and a combination of MTX and cyclosporine. The research was done in the Dermatology Outpatient Clinic of Hasan Sadikin Hospital, a tertiary care referral hospital in Bandung, West Java, Indonesia. Medical records of patients from the year 2016-2017 were collected, including data of demography, duration of treatment, body surface area involvement, psoriasis area and severity index (PASI) score, and laboratory findings such as complete hematological profiles, hepatic function, renal function, and blood sugar tests. Patients were classified into three groups: those who received MTX, cyclosporine, and a combination of MTX and cyclosporine. This research has been reviewed by the Ethics Committee at Dr. Hasan Sadikin Hospital, Bandung, West Java, Indonesia (No: LB.02.01/X.6.5/95/2021).

Only one agent or a combination agent was administered after the baseline laboratorytest except for topical treatments. Thestartingdoseoforal or subcutaneous MTX was $0.2-0.4 \mathrm{mg} / \mathrm{kg}$ body weight/week, with dose adjustment after 2-3 months based on the clinical efficacy. Oral cyclosporine was administered at $2.5-5 \mathrm{mg} / \mathrm{kg} /$ day given in two divided doses. The dose of cyclosporine was also changed based on the clinical efficacy. In cases of aggravation, the dose of cyclosporine was increased. If the patient showed a remission, the dosage was decreased to the lowest possible amount.

Psoriasis area and severity index (PASI) is the current gold standard for assessing extensive psoriasis as a method to evaluate the clinical efficacy of treatment for psoriasis. ${ }^{8}$ PASI was calculated at baseline and repeated every month of therapy. The primary endpoint of treatment was a reduction in PASI by $50 \%$ from baseline (PASI 50), and the secondary endpoints were PASI 75 and PASI 90. Treatment was thought to be successful if PASI 50 was achieved by the patient. PASI 50 was considered the primary endpoint because of limitations of followup and affordability of the drugs in our settings. PASI 90 was taken as remission. Serum creatinine for the renal function should be monitored before and after treatment of cyclosporine. ${ }^{9}$ The cyclosporine dose should be reduced if the serum creatinine increases $25 \%$ above the pretreatment level, and if it remains persistently elevated after dose reduction, cyclosporine should be discontinued. ${ }^{9}$ Hepatic effects after MTX treatment were also evaluated. Dose reduction is performed if liver transaminases exceed 2- to 3-fold normal level. ${ }^{6}$

The data were tabulated using a statistical software package for social sciences (SPSS) version 22. Statistical significant values were defined as pvalue $<0.05$.

Table 1. Clinical and demographic characteristics of patients

\begin{tabular}{|c|c|c|c|c|}
\hline \multirow[b]{2}{*}{ Variable } & \multicolumn{3}{|c|}{ Group } & \multirow[b]{2}{*}{ p-value } \\
\hline & $\begin{array}{l}\text { Methotrexate } \\
\qquad(\mathrm{n}=6)\end{array}$ & $\begin{array}{l}\text { Cyclosporine } \\
(n=18)\end{array}$ & $\begin{array}{l}\text { Methotrexate } \\
\text { and cyclosporine } \\
\text { combination } \\
(n=16)\end{array}$ & \\
\hline Age (years old) & & & & $<0.001 * *$ \\
\hline Mean \pm SD & $66.33 \pm 8.571$ & $46.05 \pm 12.191$ & $41.06 \pm 11.180$ & \\
\hline Median & 69.000 & 46.000 & 39.500 & \\
\hline Range (min-max) & $50.00-73.00$ & $13.00-65.00$ & $22.00-68.00$ & \\
\hline Sex & & & & 0.860 \\
\hline Male & $4(66.7 \%)$ & $10(55.6 \%)$ & $10(62.5 \%)$ & \\
\hline Female & $2(33.3 \%)$ & $8(44.4 \%)$ & $6(37.5 \%)$ & \\
\hline Baseline PASI & & & & 0.660 \\
\hline Mean \pm SD & $5.96 \pm 3.669$ & $7.22 \pm 5.152$ & $6.02 \pm 4.803$ & \\
\hline Median & 5.350 & 6.350 & 4.150 & \\
\hline Range (min-max) & $1.80-12.00$ & $0.50-21.00$ & $1.00-15.80$ & \\
\hline
\end{tabular}




\section{RESULT}

A total of 40 patients received MTX (6 patients), cyclosporine (18 patients), and combination therapy of MTX and cyclosporine (16 patients) in the past year. The study population comprised 24 males and 16 females ranging from 13 to 73 years $(47.10 \pm 13.9$ years). At baseline, PASI was $6.55 \pm 4.748$ (range: $0.50-21.00$ ) (Table 1). PASI was used to assess the severity of psoriasis patients in this study. Table 2 shows that psoriasis patients generally presented with mild to moderate psoriasis. PASI values less than 7 , between 7 and 12, and more than 12 are considered to indicate mild, moderate, and severe psoriasis.

Psoriasis area and severity index was calculated at baseline and after three months of treatment. Of all subjects, seven patients $(17.5 \%)$ reached PASI 90 at the end of observation. Three patients (50\%) achieved PASI 90 after three months in MTX group, with only one patient had PASI <50. Meanwhile, only three patients $(16.7 \%)$ in cyclosporine group had PASI 90. Interestingly, only one patient $(6.3 \%)$ in group MTX and cyclosporine attained PASI 90. The data were summarized in Table 3.

Side effects were monitored, including liver function tests and kidney function tests that performed biweekly. One patient who received cyclosporine alone had elevated liver enzymes from 14 to $85 \mathrm{U} / \mathrm{L}$ at the third month of therapy that required discontinuation of treatment. However, other patients had no biochemical changes in hepatic or kidney profiles. There was no significant difference in the change of PASI score after three months of therapy between each group $(p=0.102)$, which means there was no difference in the effectiveness of MTX, cyclosporine, and a combination treatment of MTX and cyclosporine.

\section{DISCUSSION}

Psoriasis vulgaris is a chronic and relapsing diseasewith a high burden and significant influence on the quality of life. ${ }^{10,11}$ The therapeutic options for psoriasisshould be effective and have good safety profiles. ${ }^{12}$ In this study, six patients $(50 \%)$ from the MTX group have reached almost complete remissions (PASI 90) after three months of treatment, while two patients $(33.3 \%)$ reached PASI 75 . The previous study revealed that PASI 75 was achieved in $88 \%$ of patients in about 8.5 weeks. ${ }^{13}$ Meanwhile, another study showed that $60 \%$ of patients had a good response $(80-100 \%$ reduction of PASI) after 12 weeks of MTX treatment. ${ }^{14}$ Methotrexatehas been the drug of choice of psoriasis systemic treatmentbecause of its good responses with good safety profile. ${ }^{5}$ The therapeutic effect of MTX usually emerges progressively throughout the first 4-8 weeks after treatment initiation. ${ }^{4}$

Methotrexate has main side effects, such as irreversible liver cirrhosis, bone marrow suppression, and mucosal damage. Elevation of liver enzymes is frequently reported as a side effect during MTX treatment. ${ }^{10}$ In our study, none of our patients who received MTX alone reported substantially elevated liver enzymes after 12 weeks of treatment. This finding was lower than the number of side effects reported before, which showed that two of 11 patients had elevated liver enzymes during MTX treatment. ${ }^{13}$ Choi et al.also found abnormalities of liver enzymes in two patients during MTX treatment. ${ }^{9}$ We decided that MTX is relatively safe and effective for patients in our settings.

Table 2. The number of mild, moderate, and severe psoriasis patients before treatment

\begin{tabular}{lccc}
\hline \multirow{2}{*}{ Variable } & \multicolumn{3}{c}{ Group } \\
\cline { 2 - 4 } & $\begin{array}{c}\text { Methotrexate } \\
(\mathrm{n}=6)\end{array}$ & $\begin{array}{c}\text { Cyclosporine } \\
(\mathrm{n}=18)\end{array}$ & $\begin{array}{c}\text { Methotrexate and cyclosporine } \\
\text { combination }(\mathrm{n}=16)\end{array}$ \\
\hline Baseline PASI & & & \\
Mild (PASI $<7)$ & $4(66.67 \%)$ & $11(61.11 \%)$ & $10(62.5 \%)$ \\
Moderate (PASI 7-12) & $2(33.33 \%)$ & $4(22.22 \%)$ & $3(18.75 \%)$ \\
Severe $(>12)$ & 0 & $3(16.67 \%)$ & $3(18.75 \%)$ \\
\hline
\end{tabular}

PASI: Psoriatic Area and Severity Index

Table 3. Decrement of Psoriatic Area and Severity Index after three months of therapy

\begin{tabular}{lcccc}
\hline \multirow{2}{*}{ Variable } & \multicolumn{4}{c}{ Group } \\
\cline { 2 - 3 } & $\begin{array}{c}\text { Methotrexate } \\
(\mathrm{n}=6)\end{array}$ & $\begin{array}{c}\text { Cyclosporine } \\
(\mathrm{n}=18)\end{array}$ & $\begin{array}{c}\text { Combination of methotrexate } \\
\text { and cyclosporine }(\mathrm{n}=16)\end{array}$ & P-value \\
\hline Decrement of PASI & $1(16.7 \%)$ & $5(27.8 \%)$ & $6(37.5 \%)$ & 0.102 \\
PASI <50 & $0(0.0 \%)$ & $7(38.9 \%)$ & $8(50.0 \%)$ & \\
PASI 50 & $2(33.3 \%)$ & $3(16.7 \%)$ & $1(6.3 \%)$ \\
PASI 75 & $3(50.0 \%)$ & $3(16.7 \%)$ & $1(6.3 \%)$ & \\
PASI 90 & &
\end{tabular}

PASI: Psoriatic Area and Severity Index 
Limitations in the use of cyclosporine in the psoriasis treatment have to be considered. Long-term continuous use of cyclosporine is not recommended due to nephrotoxicity and hypertension. ${ }^{10}$ Meanwhile, the cyclosporine group in our study showed different results as three patients (16.7\%) reached PASI 90 and PASI 75. Meanwhile, seven patients (38.9\%) had PASI 50, and one patient who received cyclosporine had elevated liver enzymes and elevated serum creatinine level at the third month of therapy that required discontinuation of treatment. A previous study also showed the abnormality in uric acid level in one patient during cyclosporine treatment. ${ }^{10}$ The side effect of cyclosporine is renal dysfunction, associated with long-term cyclosporine maintenance. ${ }^{2}$ However, intermittent short courses of cyclosporine are correlated with transient and reversible renal functions. ${ }^{2}$ Then, we decided to stop cyclosporine treatment in our patient due to the fear of nephrotoxicity in this study.

Rotational therapy was also applied in the treatment of psoriasis, as quick switching from one treatment to another treatment. Among the various combinations, rotational therapy using cyclosporine and MTX was suggested to be a good combination of rotation therapy that can minimize laboratory adverse events with cyclosporine or MTX in treating psoriasis. ${ }^{10}$ According to Choi et al., the rotational approaches using cyclosporine and MTX reduced the possibility of the development of nephrotoxicity. In addition to other advantages such as quick switching from one agent to another, the rotational therapy using cyclosporine and MTX can minimize the adverse events during psoriasis' systemic treatment. ${ }^{10}$ We also have to consider the elevation of liver enzymes for the MTX treatment and readjust the dosage or switch to cyclosporine if there are any elevated liver enzymes. Though the adverse effects of cyclosporine were more common than those psoriasis patients who used MTX. $^{3}$

The combination of cyclosporine and MTX reduces the dosages and the side effects of each agent, allowing better disease control with less toxicity. ${ }^{2,10}$ MTX combined with cyclosporine is also effective in recalcitrant generalized pustular psoriasis forms. A combination of 7.5-15 $\mathrm{mg} /$ week of MTX with $3 \mathrm{mg} / \mathrm{kg} /$ day of cyclosporine was found to produce better clearance of psoriasis and fewer side effects than monotherapy with either agent. Furthermore, one study of severe psoriasis had clinically significant improvement after treatment with the combination of MTX, given intramuscularly as a single weekly dose of $10 \mathrm{mg}$, and cyclosporine at an amount of $3.5 \mathrm{mg} / \mathrm{kg} / \mathrm{day}$, for a median period of 9.5 weeks with minor, transient, and manageable short-term side effects. $^{2}$

In this study, we also analyzed the effect of a combination treatment using MTX and cyclosporine. Interestingly, only one $(6.3 \%)$ patient in the group MTX and cyclosporine attained PASI 90 at the end of treatment, while eight patients $(50 \%)$ had PASI 50. We found no laboratory abnormalities in renal and liver functions during three months of treatment. This finding supported the study result of Mohanan et al. that showed a combination of MTX and cyclosporine was safe and effective for psoriasis and had no irreversible adverse severe effects. ${ }^{3}$

This study was a retrospective study, and there was a possible risk of bias. A prospective randomized controlled study is needed in the future to approve the effectiveness and safety of a combination treatment with MTX and cyclosporine.

Based on our results, combination treatment of MTX and cyclosporine is as effective as monotherapy of MTX or cyclosporine. Our results also support that this three months combination therapy is relatively safe and effective forpsoriasisvulgaris patients.

\section{REFERENCES}

1. Gudjonsson JE, Elder JT. Psoriasis. In: Kang S, Amagai M, Bruckner AL, Enk AH, Margolis DJ, McMichael AJ, editors. Fitzpatrick's dermatology in general medicine. 9th edition. New York: McGraw-Hill. 2019. P. 457-97.

2. Colombo MD, Cassano N, Bellia G, Vena GA. Cyclosporine regimens in plaque psoriasis: an overview with special emphasis on dose, duration, and old and new treatment approaches. Sci World J 2013;1-11.

3. Mohanan S, Ramassamy S, Chandrashekar L, Thappa DM. A retrospective analysis of combination methotrexate-cyclosporine therapy in moderate-severe psoriasis. J Dermatolog Treat 2014;25:50-3.

4. Ruiz-Villaverde R, Sanchez-Cano D, GarridoColmenero C, Fernández-Crehuet P. Experience with subcutaneous methotrexate for the treatment of moderate-to-severe psoriasis. Clin Case Rep 2015;5:1-4.

5. Yelamos O, Puig L. Systemic methotrexate for the treatment of psoriasis. Exp Rev Clin Immunol 2015;11:553-63.

6. Honaker JS, Korman NJ. Cytotoxic and antimetabolic agents. In: Kang S, Amagai M, Bruckner AL, Enk AH, Margolis DJ, McMichael AJ, editors. Fitzpatrick's dermatology in general medicine. 9th edition. New York: McGraw-Hill. 2019. P. 3463-92. 
7. Raut AS, Prabhu RH, Patravale VB. Psoriasis clinical implications and treatment: a review. Crit Rev Ther Drug Carrier Syst 2013;30(3).

8. Žurauskas M, Barkalifa R, Alex A, et al. Assessing the severity of psoriasis through multivariate analysis of optical images from nonlesional skin. Sci Rep 2020;10:9154.

9. Kurtzman D, Vleugels RA, Callen J. Immunosuppresive and immunomodulatory drugs. In: Kang S, Amagai M, Bruckner AL, Enk AH, Margolis DJ, McMichael AJ, editors. Fitzpatrick's dermatology in general medicine. 9th edition. New York: McGraw-Hill; 2019. P. 3430-517.

10. Choi CW, Kim BR, Ohn J, Youn SW. The advantage of cyclosporine a and methotrexate rotational therapy in long-term systemic treatment for chronic plaque psoriasis in a real world practice. Ann Dermatol 2017;29:55-60.

11. Bożek A, Reich A. The reliability of three psoriasis assessment tools: Psoriasis area and severity index, body surface area and physician global assessment. Adv Clin Exp Med 2017;26:851-6.

12. Czarnecka-Operacz M, Sadowska-Przytocka A. The possibilities and principles of methotrexate treatment of psoriasis - the updated knowledge. Postepy Dermatol Alergol 2014;31:392-400.

13. Dogra S, Mahajan R. Systemic methotrexate therapy for psoriasis: past, present and future. Clin Exp Dermatol. 2013;38(6):573-88.

14. Duara G, Kumar D. A prospective study of clinical efficacy of methotrexate, cyclosporine and azathioprine in psoriasis. J Evid Based Med Healthcare 2016:3:117-9. 